\title{
Estimation of snow damage in an urban area with heavy snowfall
}

\author{
Seiji Kamimura and Teruyoshi Umemura \\ Nagaoka University of Technology, Nagaoka, Niigata 940-21, Japan
}

\section{SUMMARY}

In cities bordering the Sea of Japan where snowfall is heavy, residents cannot maintain their urban life without snow damage reduction or snow disaster prevention systems. In planning those systems an economic estimation is necessary, which requires quantification of the amount of snow damage occurring in a given place.

We have defined amounts of snow damage per day expressed in terms of money, considering it intrinsic to place and existing materials; its value is estimated for a 20 block section in Nagaoka City described in a previous paper (Uemura and others, 1992), for 24 January 1983. Here we give a convenient way to calculate an annual amount of snow damage, as follows.

The daily amount of snow damage, $h\left(\right.$ Yend $^{-1}$, or Yen $\mathrm{m}^{2} \mathrm{~d}^{-1}$ ), has been expressed as

$$
h=k e+e^{\prime \prime}
$$

where $k$ represents the seasonal drop in utilization, $e$ expense in non-snowy times and $e^{\prime \prime}$ the expense only in snowy times. The annual amount of snow damage can be expressed as an accumulation of the daily amount of snow damage shown in Equation (1):

$$
\begin{aligned}
H & =\Sigma h, \\
E & =\Sigma e \\
\text { and } E^{\prime \prime} & =\Sigma e^{\prime \prime},
\end{aligned}
$$

where $\Sigma$ means accumulation of daily amounts for 365 days. If we take annual mean seasonal drop factor as $\bar{k}=$

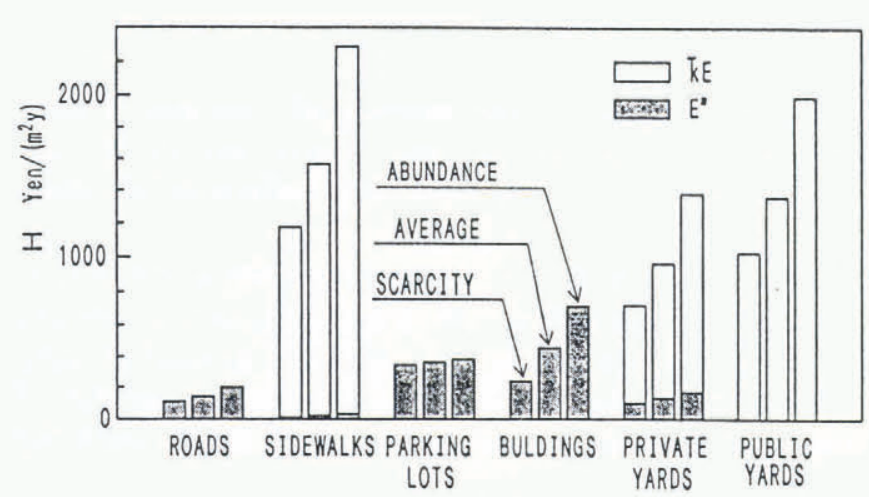

Fig. 1. Areal annual amount of snow damage for 6 SDAF: abundance (1985-86), average (1982-83) and scarcity (1988-89).
Table 1. Calculated annual amounts of snow damage for the urban area of Nagaoka City in $¥ a^{-1} \times 10^{6}$

\begin{tabular}{cccc}
\hline & & & \\
& Abundance \\
$1985-86$ & Average & Scarcity \\
& & & \\
\hline & & & \\
$H$ & $1582-83$ & $1988-89$ \\
$\bar{k} E / H, \%$ & 70.3 & 10378 & 7504 \\
& & 69.8 & 72.6 \\
\hline
\end{tabular}

$(\Sigma k e) / \Sigma e$, then the annual amount of snow damage, $H$, is shown as follows,

$$
H=\bar{k} E+E^{\prime \prime}
$$

Usually $E$ is known from past data and the daily amount is expressed as $e=E / 365$ on average, so it follows that $\bar{k}=(\Sigma k) / 365$. Now we use the following approximation: if any measures are taken to a part of a snow damage appraisal factor (SDAF), the value of $k$ is expressed as the value of unity minus the ratio of the area of the part. If the area does not change during snow-cover days, by using the number of snow-cover days, $D, \bar{k}$ becomes

$$
\bar{k}=\frac{\Sigma k}{365}
$$

because $k$ is constant during snow-cover days and zero on other days.

Using this method, we calculate an annual amount of snow damage to the SDAF existing in the place to be assessed, and show the amounts in every district in Nagaoka City for representative amounts of snow.

It has been made clear, by calculation of areal mean amounts of snow damage to SDAF (shown in Fig. 1), that snow damage is already considerably reduced by snowremoving machines and snow-melting pipe systems in roads and parking lots, but remains quite high in sidewalks and public and private areas left without any measures.

Annual amounts of snow have an approximately linear effect on the amount of snow damage, through the amount of snowfall, maximum snow depth or snow-cover days. No catastrophic effects have been observed as far as the present calculation is concerned. 
Economic estimation of construction of snow-removing ditches using the amount of snow damage has been made in an urban area of $20.45 \mathrm{~km}^{2}$. Construction is economical in the commercial district and neighborhood in a year of snow scarcity, and also in years of snow abundance in residential districts.

\section{ACKNOWLEDGEMENTS}

We thank Nagaoka City Office which supplied much of the data used. This study was supported in part by members of the Conference of Development and Research for an Integrated System of Removal, Storage and Airconditioning Use of Snow.

\section{REFERENCE}

Umemura, T., S. Kamimura and H. Otaki. 1992. Snow damage on an urban area with heavy snow fall: definition of the amount of snow damage and appraisal. Journal of Natural Disaster Science, 13(1), 111.

The accuracy of references in the text and in this list is the responsibility of the authors, to whom queries should be addressed.

\title{
Utilization of snow with a snow compactor
}

\author{
NOBUO MIYAZAKI, \\ Climate Engineering Inc., 541-4, Saiho, Nakasato-Ville., Naka-Uonuma, Niigata 949-84, Japan \\ TOSIYUki Harada, Sigeru Kondou, \\ Kannsai Electric Power Co. Inc., 3-22, 3-Chome, Nakanosima, Kita-ku, Osaka 530, Japan \\ TATUO HASEMI \\ Science of Snow and Ice Co. Ltd., 1-9, 3-Chome, Azabudai, Minato-ku, Tokyo 106, Japan
}

\section{SUMMARY}

In recent years many attempts have been made to utilize snow in the snowy areas of Japan. Among basic technologies for snow utilization, compaction and shaping of snow are important in order to use storage space effectively and to delay snow melt.

A snow compactor with a "screw-feed" system was developed: collected natural snow is compressed by a screw into a solid cylindrical snow column. Extrusion speed of the compressed column is about $60 \mathrm{~cm} \mathrm{~min}^{-1}$ and the productivity of this snow compressor is over $0.5 \mathrm{th}^{-1}$.

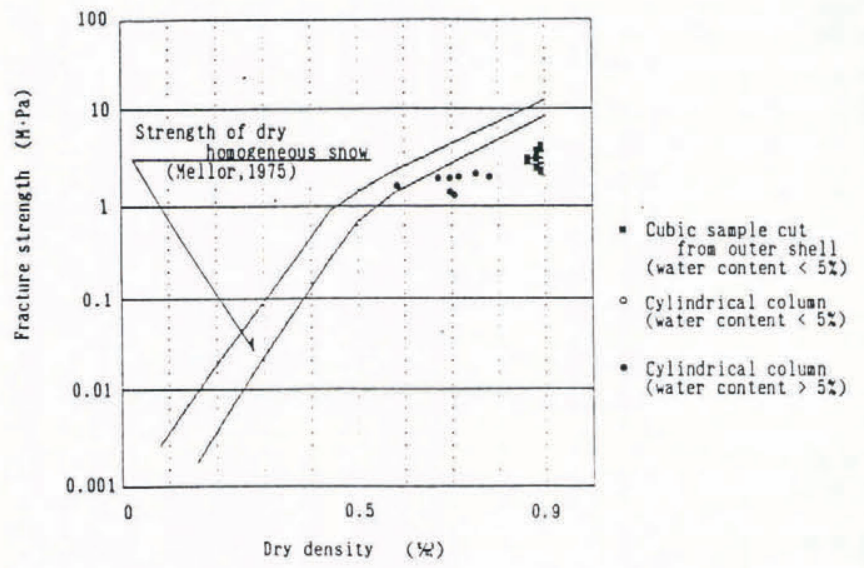

Fig. 1. Compressive fracture strength (samples tested immediately after extrusion).

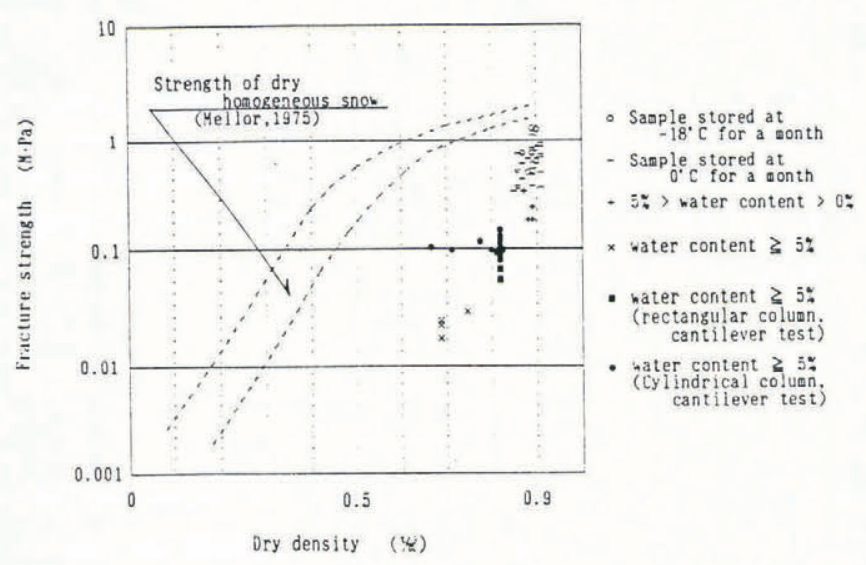

Fig. 2. Tensile fracture strength.

The wet density of the compacted columns is over $790 \mathrm{~kg} \mathrm{~m}^{-3}$. Pressure at the screw blades is 15$30 \mathrm{kgf} \mathrm{cm}^{-2}$ during continuous production of snow columns.

The cross-section of a compacted-snow column is circular or rectangular. The center part of the column, where coarse ice grains are observed, is mechanically weak and thought to be less compacted. The outer shell of the column is more transparent with many small air bubbles.

Wet density of the resultant snow column was measured as $790-940 \mathrm{~kg} \mathrm{~m}^{-3}$, which is two to four times greater than the original snow density. Water content was 